\title{
Potential regenerative treatment strategies for intervertebral disc degeneration in dogs
}

\author{
Frances C Bach ${ }^{1 *}$, Nicole Willems', Louis C Penning ${ }^{1}$, Keita Ito ${ }^{2,3}$, Björn P Meij ${ }^{1}$ and Marianna A Tryfonidou
}

\begin{abstract}
Pain due to spontaneous intervertebral disc (IVD) disease is common in dogs. In chondrodystrophic (CD) dogs, IVD disease typically develops in the cervical or thoracolumbar spine at about 3-7 years of age, whereas in nonchondrodystrophic (NCD) dogs, it usually develops in the caudal cervical or lumbosacral spine at about 6-8 years of age. IVD degeneration is characterized by changes in the biochemical composition and mechanical integrity of the IVD. In the degenerated IVD, the content of glycosaminoglycan (GAG, a proteoglycan side chain) decreases and that of denatured collagen increases. Dehydration leads to tearing of the annulus fibrosus (AF) and/or disc herniation, which is clinically characterized by pain and/or neurological signs. Current treatments (physiotherapy, antiinflammatory/analgesic medication, surgery) for IVD disease may resolve neurological deficits and reduce pain (although in many cases insufficient), but do not lead to repair of the degenerated disc. For this reason, there is interest in new regenerative therapies that can repair the degenerated disc matrix, resulting in restoration of the biomechanical function of the IVD. CD dogs are considered a suitable animal model for human IVD degeneration because of their spontaneous IVD degeneration, and therefore studies investigating cell-, growth factor-, and/or gene therapy-based regenerative therapies with this model provide information relevant to both human and canine patients. The aim of this article is to review potential regenerative treatment strategies for canine IVD degeneration, with specific emphasis on cell-based strategies.
\end{abstract}

Keywords: Intervertebral disc, Degeneration, Spine, Dog, Regenerative medicine, Mesenchymal stem cell, Notochordal cell

\section{Introduction}

The intervertebral disc (IVD) arises from the embryonic notochord and mesenchyme and develops into a complex tissue that permits movement between vertebrae and provides flexibility and integrity to the spine [1]. The IVD consists of the vertebral endplates (EPs), the annulus fibrosus (AF), and the nucleus pulposus (NP) (Figure 1). The AF contains concentric lamellae mainly composed of collagen type I, elastin fibres, and fibroblast-like cells. Together with the hyaline cartilage EPs, it encloses the beanshaped NP [2,3]. By enabling diffusion and permeability, the EPs play an essential role in NP nutrient delivery, since the latter has no direct blood supply [2]. The NP contains a highly hydrated gelatinous matrix, mainly composed of proteoglycan and collagen type II [2]. Cations, which are

\footnotetext{
*Correspondence: F.C.Bach@uu.nl

'Department of Clinical Sciences of Companion Animals, Faculty of

Veterinary Medicine, Utrecht University, Utrecht, Netherlands

Full list of author information is available at the end of the article
}

attracted to the negatively charged proteoglycans, create a strong osmotic gradient that draws water molecules into the NP [2]. During early development, the NP contains a relatively large amount of cells and a small amount of extracellular matrix (ECM), whereas the ECM/cell ratio is high in the mature NP $[3,4]$.

IVD degeneration is characterized by changes in the biochemical composition and mechanical integrity $[2,4]$. The glycosaminoglycan (GAG, a proteoglycan side chain) content decreases and catabolic matrix metalloproteinase (MMP) activity and denatured collagen content increases - the latter creating a more rigid IVD matrix reviewed in $[2,5,6]$. Matrix repair is impaired in the avascular IVD, resulting in weakening and increased vulnerability to damage by physiologic loading. A vicious circle of continuous damage and inadequate repair develops, leading to disc degeneration rather than healing. Once the degenerative process starts, it is progressive [7]. The decrease in GAG content, and subsequent 


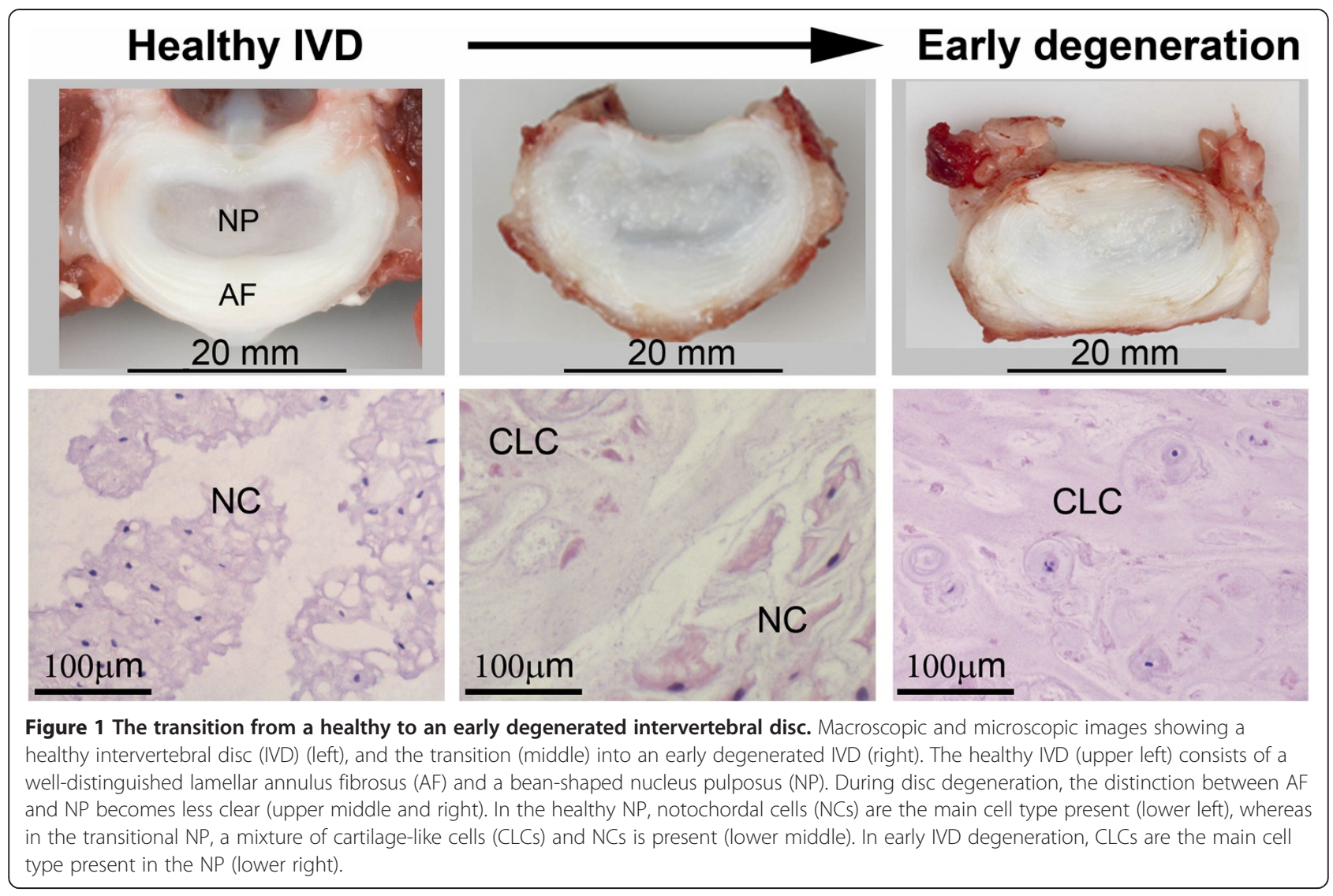

dehydration, causes a decrease in disc height [8]. Compressive forces cause increased loading on the AF, generating a concave bending load on the EPs. This change in the direction of loading forces is considered to be responsible for AF tearing, EP fracturing, and/or disc herniation. Herniation usually occurs on the dorsal side, because the ventral part of the AF is two to three times thicker than the dorsal part and because the vertebral column is normally more flexed than extended, resulting in higher tension in the dorsal part than in the ventral part [2].

Many dogs suffer from the clinical consequences of IVD degeneration, and IVD disease is a relatively common reason for euthanasia [9]. IVD degeneration impairs the function of the spinal unit (IVD, EPs, ligaments, facet joints and vertebral body), causing secondary osteoarthritic changes, bone sclerosis/spondylosis, and neurological signs and deficits due to spinal cord or nerve root compression [10]. Owners of dogs may report unilateral or bilateral lameness or paresis/ paralysis, toe dragging, low tail or neck carriage, difficulties with rising, sitting or lying down, reluctance to jump or climb, urinary or faecal incontinence, and hyperesthesia or self-mutilation [11]. Furthermore, pain is evoked by pressure applied to the affected spinal region during the clinical examination by veterinary specialists [11]. However, IVD degeneration can also be asymptomatic.

Dog breeds can be divided into chondrodystrophic (CD) and non-chondrodystrophic (NCD) breeds based on their physical appearance. CD dog breeds (e.g. Beagles and Dachshunds) have short bowlegs because of disrupted endochondral ossification. This trait has strongly been linked with IVD degeneration, which is considered to be polygenetic [5]. In CD dog breeds, IVD disease (mainly Hansen type I herniation) typically develops in the cervical (C2C6) or thoracolumbar (T11-L3) spine at about 3-7 years of age [5]. NCD dog breeds, especially large breeds, can also develop IVD disease (mainly Hansen type II herniation), but in the caudal cervical (C5-T1) or lumbosacral (L6-S1) spine at about 6-8 years of age, mostly due to trauma or "wear and tear" [5,9]. The macroscopic, histopathological, and biochemical changes as well as the diagnostics and treatment of IVD disease are rather similar in NCD and CD dogs [5,9].

Current treatments for IVD disease in dogs focus on alleviating pain and include physiotherapy, antiinflammatory/analgesic medication, and surgery. The aim of surgery for IVD disease is to relieve the compression of neural structures, and procedures include removal of the NP (nucleotomy) through fenestration of the $\mathrm{AF}$ alone or combined with partial removal of the 
vertebral roof (laminectomy) or vertebral body (ventral decompression) [12]. Above mentioned therapies may resolve neurological deficits and reduce pain (although in many cases insufficient), but they do not lead to repair of the degenerated IVD. In fact, long-term medication can cause side-effects, surgery can lead to spinal instability and adjacent segment disease, and recurrence of IVD disease may occur [12]. Therefore, there is increasing interest in regenerative therapies aimed at the biological repair of the degenerated IVD, including cellbased strategies and the use of growth factors or gene therapy. The specific aim of these therapies is to repair the degenerated disc matrix and in this way restore the biomechanical function of the IVD [13,14]. Research in the field of regenerative medicine increases our understanding of disease processes and findings may ultimately be translated into therapeutic interventions for veterinary patients. The focus of this review is to discuss potential regenerative treatment strategies for canine
IVD degeneration, with specific emphasis on cell-based strategies.

\section{Models to develop new regenerative treatment strategies for IVD degeneration}

Regenerative treatment options are developed in vitro and then extrapolated to in vivo animal models before being used in the clinic. Commonly used in vitro cell culture models are 2D monolayer and 3D cell pellet, filter, or alginate bead cell culture (Figure 2). A major disadvantage of these in vitro models, however, is that the native tissue environment is lost during cell isolation, which might affect cell behaviour [15]. Thus cell culture experiments may not adequately represent the in vivo situation, and care should be taken when interpreting the results of such studies. For this reason, tissue explant systems have been developed, in which an environment is created that resembles the in vivo situation [16]. However, a drawback of NP explants is that swelling pressure

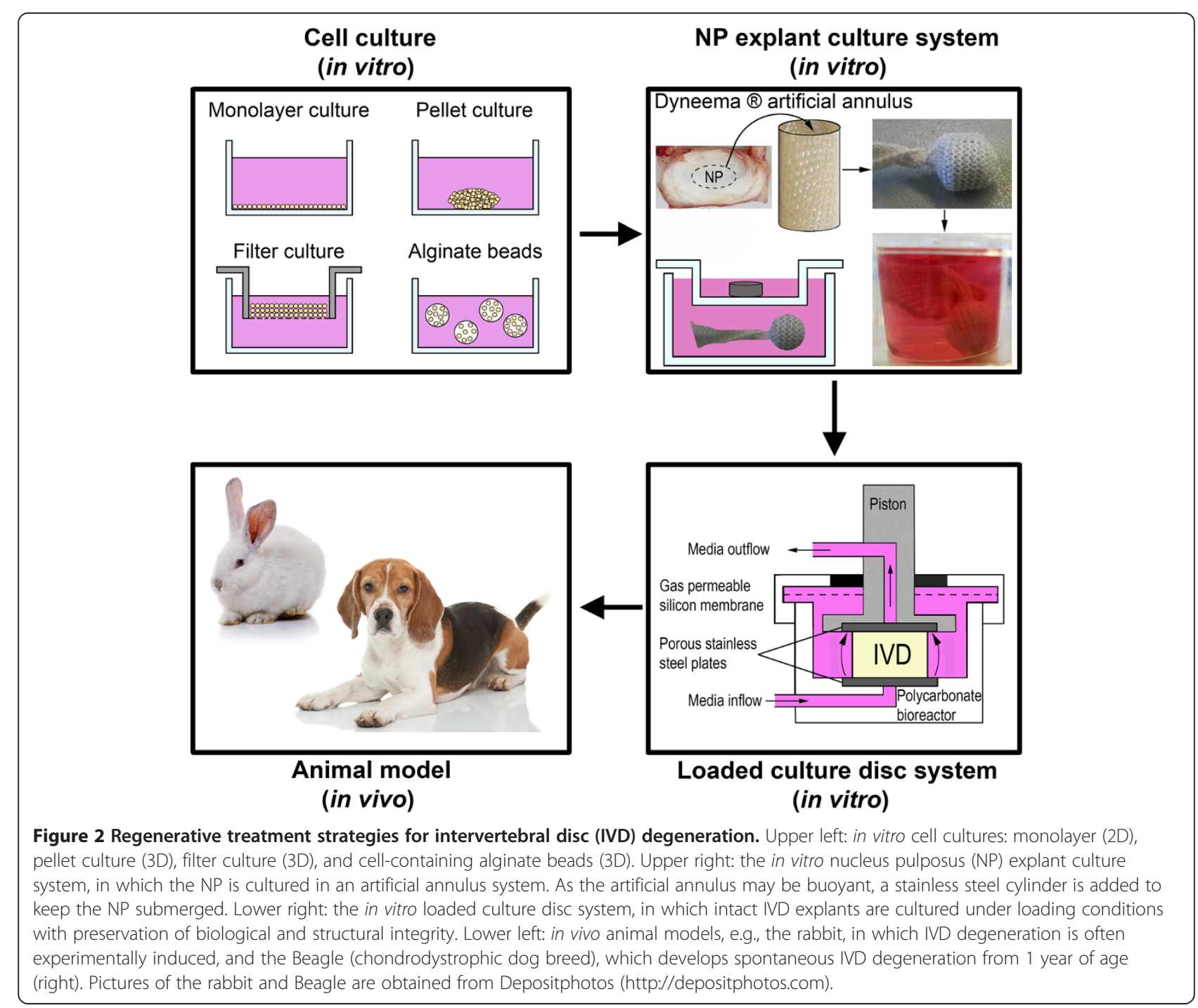


is no longer balanced by the AF and hyperosmolarity within the NP is difficult to maintain, which results in NP tissue swelling. A special fibre jacket (artificial annulus) has been developed to mimic the AF in the socalled NP explant system, creating a physiological model to test the efficacy of regenerative therapies for IVD degeneration [15,17]. To mimic the in vivo situation even closer, whole organ culture bioreactor systems, e.g. the loaded culture disc system, have been developed, in which intact IVD explants, including AF, NP, and EPs, are kept alive under loading conditions for as long as 6 weeks with preservation of biological and structural integrity $[18,19]$. The last step for validating regenerative medicine treatment strategies involves the use of in vivo animal models. Models based on mice, rats, rabbits, goats, and dogs with experimentally induced IVD degeneration have often been used [20], but these animals, with the exception of dogs, do not spontaneously develop IVD degeneration and disease. Interestingly, some in vivo IVD regenerative studies have been performed with laboratory dogs with experimentally induced IVD degeneration [21-26]. To our knowledge, dogs with naturally occurring IVD degeneration have not been used, even though it is recognized that CD dog breeds are a suitable animal model of spontaneous IVD degeneration $[9,13]$.

\section{Regenerative treatment options \\ Cell-based therapies}

The synthesis of NP matrix can be stimulated by means of growth factors and/or gene therapy. However, since there are relatively few cells in the degenerated IVD and cell viability is impaired, stimulation of the remaining cells may be insufficient to achieve repair [13]. Cell-based therapies may overcome this problem (Figure 3). Thus far, cellbased treatment strategies have mainly used chondrocytelike cells (CLCs), mesenchymal stromal (stem) cells (MSCs), and notochordal cells (NCs) [13]. These cell types are discussed below with regard to their characteristics, effectiveness, benefits, and drawbacks.

\section{Chondrocyte-like cells (CLCs)}

The cells found in the degenerating NP are similar, but not identical, to articular chondrocytes and are therefore termed chondrocyte-like cells (CLCs) [27]. Insertion of autologous and allogeneic CLCs in the NP has been

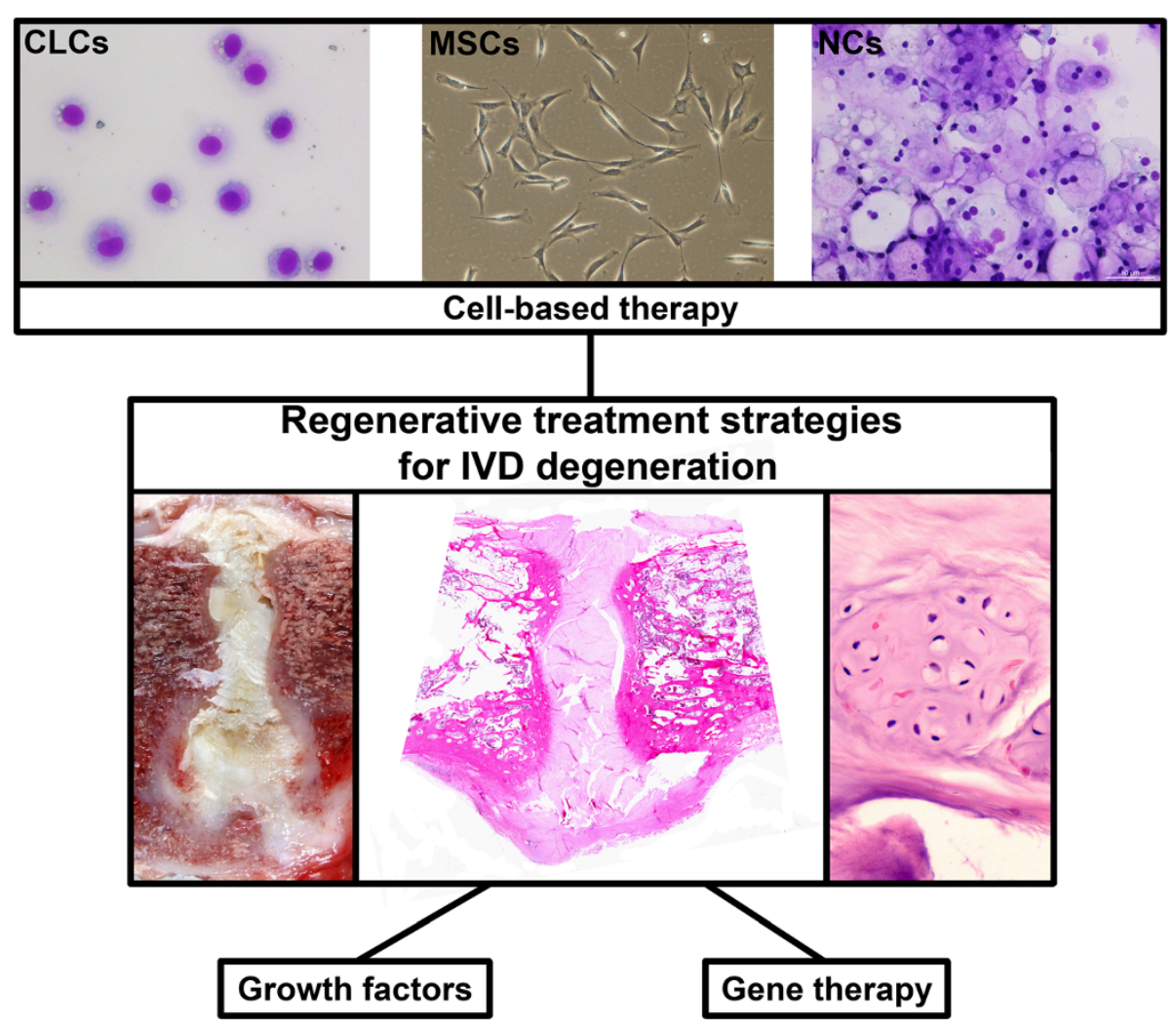

Figure 3 Regenerative treatment options for intervertebral disc (IVD) degeneration: cell-based therapy, growth factors, and gene therapy. Cell-based treatment strategies have mainly used chondrocyte-like cells (CLCs), mesenchymal stromal (stem) cells (MSCs), and notochordal cells (NCs). The lower images show a severely degenerated IVD macroscopically (left) and on haematoxylin \& eosin staining (middle and right). The lower right image shows a cluster of CLCs, which are frequently observed in (severely) degenerated IVDs. 
shown to retard IVD degeneration in various species without inducing any appreciable host-versus-graft response $[21,28,29]$. This is in line with the notion that the IVD is immune privileged due to its avascularity [30] and the expression of Fas ligand (FasL), which induces apoptosis of invading Fas-bearing T-cells [24,31].

Although CLCs have regenerative potential, the severity of IVD degeneration can limit their regenerative capacity. Degenerated CLCs may lose specific characteristics (e.g. their chondrogenic potential), making them less suitable for tissue engineering purposes. CLC transplantation has its limitations because these cells can only be obtained from herniated discs, cell numbers are low, and extensive expansion before transplantation is needed [32]. Preconditioning expanding CLCs with AF cells, however, improved the performance of CLCs in a rabbit IVD degeneration model [33]. Also, co-culture of CLCs with MSCs enhanced the biological activity and viability of CLCs in vitro, as evidenced by increased cell proliferation and matrix synthesis [32,34-39]. The latter is consistent with the well-known beneficial effect of MSCs on articular chondrocytes [40].

\section{Mesenchymal stromal (stem) cells (MSCs)}

NP-derived cells are of limited availability [41] and, therefore, current regenerative strategies focus on stem cells, particularly MSCs. MSCs are emerging as a leading cellular therapy for several diseases, since they can easily be isolated from a variety of tissues, including bone marrow, adipose and synovial tissue, muscle, placenta, and umbilical cord blood. MSCs can differentiate into different cell types, such as osteoblasts, adipocytes, chondrocytes, myocytes, and neural cells [42,43], depending on their environment [7]. In addition, MSCs have immunosuppressive properties and secrete trophic/growth factors (anti-apoptotic, stimulation of proliferation and differentiation) that support regenerative processes [43-45]. The unique combination of these properties makes MSCs highly suitable for tissue replacement therapies. Bi-directional intercellular secretion and transfer of membrane-bound components (e.g. microvesicles) has been proposed as a mechanism of cellular communication between MSCs and CLCs, and not cell fusion or gap-junctional communication. In this way, soluble, cellular or nuclear (e.g. functional gene) components can be transferred between the two cell types, causing phenotypic alterations [46].

In vivo injected MSCs can maintain their viability and proliferate within the IVD [47]. Bone marrow-derived stem cell (BMSC) transplantation was found to counteract IVD degeneration and/or increase the proteoglycan content of IVDs in experimental rabbit and mouse models [7,30,48-51]. Adipose-derived stem cell (ASC) and BMSC delivery has also been shown to promote disc regeneration in an experimentally induced IVD degeneration in (Beagle [24]) dogs [25]. In addition, MSCs may be responsible for sustaining the IVD immune privilege by differentiating into cells expressing FasL [24]. The optimal number of BMSCs for intradiscal delivery (4 weeks after NP aspiration) was estimated in Beagles, based on the survival rate and apoptosis of CLCs in BMSCinjected IVDs [26]. In IVDs injected with $10^{6}$ MSCs, the microenvironment and ECM abundance was maintained, whereas the injection of fewer cells $\left(10^{5} \mathrm{MSCs}\right)$ resulted in fewer viable cells and the injection of more cells $\left(10^{7}\right.$ MSCs) resulted in more apoptotic cells [26].

Despite the promising experimental studies and clinical trials, there is uncertainty about the chondrogenic differentiation of MSCs. Can MSCs differentiate into hyaline articular chondrocytes instead of CLCs? MSCs have been reported to undergo chondrocytic differentiation and form repair tissue that resembles hyaline cartilage during in vitro studies or after transplantation into the NP [30,52]. Morphologically, articular cartilage and NP tissue consist of chondrocytes surrounded by ECM, but there are considerable differences in composition and biomechanical function [53]. However, properly differentiated MSCs express chondrogenic cell marker genes and have a proteoglycan:collagen ratio closer to that of NP tissue than that of hyaline articular cartilage [53-55].

Recently, healthy and degenerated NPs of various species, including dogs, have been reported to contain multipotent NP progenitor cells (NPPCs) $[10,27,56,57]$. These NPPCs express genes typical for stem cells, but differ from MSCs in the higher expression of the Nanog "stemness" gene [10]. NPPCs are able to differentiate into the chondrogenic lineage in vitro, and to survive in the aneural, avascular, hypoxic NP [10,14]. Thus, NPPCs might be appropriate for use in regenerative strategies to treat IVD degeneration.

\section{Notochordal cells (NCs)}

The notochord is a mesodermal, rod-like structure that defines the primitive axis of the body and serves as the centre of development of the axial skeleton during embryogenesis. Notochordal signals generate a mesenchymal peri-notochordal sheath, which eventually gives rise to the AF, EPs, and vertebral bodies [8]. The notochord condenses within the primitive AF to form the NP $[1,4]$. The composition of the NP changes as the IVD matures: the number of cells of notochordal origin decreases and the smaller CLCs increase in number [4] (Figure 1). NCs are characterized by their morphology: they are large and have cytoplasmic vesicles, the content and function of which are still debated [8]. NCs are usually found in clusters and secrete matrix rich in proteoglycan and collagen type II [2]. They have considerable regenerative 
potential and restorative capacity for other cells (CLCs and MSCs), which makes them an interesting focus for regenerative strategies.

Loss of the NC population is associated with the early development of IVD disease [58], and thus restoring the NC population may help to delay or even reverse IVD degeneration [14]. The NC population undergoes speciesspecific changes $[4,8]$. Most studies report that in humans, NCs disappear when they are about 7-10 years of age, whereas the age of onset of disc degeneration is 3050 years [8]. This means that CLCs also reside in healthy human IVDs. However, in dogs, NCs are replaced by CLCs at about 1 year of age in CD breeds, but remain the predominant cell type until middle/old age in NCD breeds $[4,5,14]$. In general, NCs are not present in degenerated canine IVDs.

Interestingly, intradiscal MSC injection increased the number of NCs and matrix deposition in murine degenerated IVDs [30]. This suggests that MSCs can promote NC proliferation and/or prevent $\mathrm{NC}$ apoptosis and that the anabolic NC function can be stimulated by MSCs. Taking into consideration the recently described NPPC population (which shows stem cell characteristics) in healthy and degenerated IVDs, it is tempting to hypothesize that NPPCs may be in cross-talk with resident NCs and have a functional role in the differentiation and maintenance of NCs.

What is the role of NCs in the IVD degeneration process and hence their potential function in IVD regeneration? The NCs may have a dual regenerative role: they may instruct CLCs and/or replenish by differentiating into CLCs. NCs may serve as 'organizer' cells, influencing the surrounding NP-cell homeostasis to maintain $\mathrm{NP}$ integrity. It seems reasonable to consider NCs as a potential source of growth factors that stimulate NP matrix synthesis [59-63], given the signalling role of the notochord during embryonic development [41]. NCconditioned medium (NCCM; medium in which NCs or $\mathrm{NC}$-containing tissue is cultured for 4 days and comprises $\mathrm{NC}$-secreted soluble factors) has the potential to increase NP GAG production and cell proliferation [61-63]. Furthermore, both NCCM and CLC + NC coculture stimulate the in vitro differentiation of MSCs into a NP-like phenotype with a high chondrogenic matrix production $[36,39,42,59,60,64,65]$. NCs may maintain the young NP phenotype by secreting factors that suppress cell death and by influencing genes that regulate IVD anabolic activity and matrix protection [66]. Attempts have been made to identify, isolate, and/ or synthesize the bioactive factors in NCCM for use in therapeutic interventions [61]. The matrix proteins clusterin and tenascin, and connective tissue growth factor (CTGF) have been proposed to be the bioactive factors in NCCM $[60,67,68]$. Indeed, CTGF has been shown to promote matrix production, proliferation, differentiation, and cell migration and to inhibit apoptosis, effects that prevent the development of IVD degeneration [67-69].

However, NCs are also considered to be 'progenitors' of the CLC population. It is much debated whether the chondrification of the maturing IVD is due to the differentiation of NCs into a CLC-like phenotype (stem cell function) or apoptosis of the NCs followed by invasion of CLCs from other locations, e.g. the EPs and/or inner AF $[27,58]$.

There are several arguments for and against the notion that NCs are CLC progenitor cells. The first argument that disputes the progenitor function is the considerable difference in cell morphology and size of CLCs (17$23 \mu \mathrm{m})$ and NCs $(25-85 \mu \mathrm{m})[1,8]$. Secondly, NCs and NCCM are both able to stimulate the migration of EP chondrocytes [70], which makes the NC organizer function more likely than the progenitor function. Thirdly, two cell types have been detected in the developing notochord: large vacuolated cells and smaller nonvacuolated cells [71]. Thus, the presumed origin of NP tissue, i.e. the notochord, seems to contain cells that appear similar to those detected in the NP itself. Fourthly, the profile of gene expression is different in NCs and CLCs, which also opposes the progenitor function status of NCs [72]. Fifthly, the self-renewal of NCs occurs infrequently and is not unlimited, aspects that oppose the stem/progenitor cell function [58]. Lastly, Brachyury expression - often considered a NC marker and required for the differentiation of mesoderm into notochord [3] was not detected in the human adult NP, which may argue against the hypothesis that both NC and CLCs are derived from the notochord [73]. The expression of this NC marker can, however, simply be lost during (trans) differentiation of NCs into CLCs.

In contrast, there are several arguments in favour of the NC progenitor theory. Firstly, NCs decrease and CLCs increase in number during ageing and disc degeneration, which could be explained by the transformation of NCs into CLCs [1]. Histological and automated live cellimaging studies of degenerated IVDs show that NCs can differentiate into cells morphologically similar to CLCs $[58,74]$. Secondly, NCs have the ability to renew themselves in vitro [58]. Thirdly, chondrocyte volumes can vary about 10 -fold in the growth plate, which counteracts the argument that the differences in cell size are too large for NCs to be a progenitor for CLCs. This variation in cell morphology and size can be explained by different maturation stages and/or cell function [1,3]. Porcine NCs have been shown to exhibit a significant variation in cell morphology, size, and number [75], implying that NC morphology can change with time. Fourthly, it is known from growth plate chondrocytes that, within a single cell population, cells of different sizes and/or location can 
express different gene profiles, which could explain the difference in gene expression profiles in NCs and CLCs $[1,3]$. In fact, the gene expression of NCs and CLCs showed substantial overlap, and Brachyury expression remained constant during IVD degeneration when NCs were replaced by CLCs [58,76]. Fifthly, NCs and CLCs have been shown to synthesize proteoglycans at the same rate [58], which indicates that they have a comparable capacity to produce matrix. In contrast, others found that NCs synthesized proteoglycans at significantly greater rates than CLCs [77]. However, in this study, the CD dogs (donors of the CLCs) were older and had a higher disc degeneration grade than the NCD dogs (donors of the NCs), which could have influenced the study outcomes. Sixthly, trace lineage studies indicate that both NCs and CLCs are derived from the embryonic notochord, suggesting that NCs are precursors of CLCs [78,79]. Lastly, there is no marker that is homogenously expressed within a specific population (NC or CLC) and, therefore, it is impossible to state that both cells of notochordal and mesenchymal origin are present within the IVD [1,3].

There are some points of interest concerning the design of experiments investigating $\mathrm{NC}$-based regenerative strategies for the treatment of IVD degeneration. Some species of experimental animals retain NCs throughout life, whereas others lose them during development and ageing, which may considerably influence experimental outcomes. For example, most studies report that NCs are present in skeletally mature non-chondrodystrophic dogs, pigs, ferrets, rabbits, rats, and mice $[4,5,8,41]$, whereas in chondrodystrophic dogs, goats, horses, cows, and sheep, they disappear before skeletal maturity is reached $[4,5,8,80]$. In contrast, others favor the hypothesis that in all animal species, including humans, NCs remain in the NP throughout life [3]. It is important that inter-species differences are taken into consideration and that research results are interpreted with care. Furthermore, NC isolation has the disadvantage of a low purity or yield [58], which is further complicated by the lack of specific markers for NCs [8]. Brachyury, and Cytokeratin 8 or 19 have been proposed as NC markers $[3,81,82]$ but they are not very specific and show interspecies variation [76]. Additional obstacles are the slow growth of NCs and their sensitivity to the external environment [58]. It is essential that culture conditions are optimized, so that NCs do not lose their characteristics. Thus far, culture media $\mathrm{pH}$, glucose concentration, osmolality, and $\mathrm{O}_{2}$ and $\mathrm{CO}_{2}$ percentages have been shown to affect maintenance of the NC-phenotype in culture $[69,83]$.

\section{Growth factors}

Stimulation of cell proliferation and/or matrix synthesis with exogenous growth factors alters IVD homeostasis either by inhibiting catabolic and/or by stimulating anabolic processes [84]. Several growth factors have been tested in vitro and most have been shown to successfully decrease cell apoptosis and/or to enhance chondrogenic matrix production, and/or to direct MSC differentiation towards a NP-like phenotype. Growth factors have also been proven effective in vivo in animal models with experimentally induced IVD degeneration (Additional file 1). However, to our knowledge there have been no studies of growth factors tested in animal models with naturally occurring IVD degeneration.

The half-life and solubility of growth factors, the proper carrier, and the presence of inhibitors need to be taken into consideration when growth factors are used in regenerative strategies [84]. Since the NP is a confined, avascular space, the injected factor may be retained for long time. Some factors have been shown to bind to the ECM and metabolic changes following a single growth factor injection might be sustained, potentially leading to longlasting effects [84]. If a growth factor has a short half-life, it can be administered by sustained delivery systems. Since degenerated discs contain relatively few cells, the injection of growth factors may not produce an optimal therapeutic effect [84]. Combined cell- and growth factor-based therapy may solve this problem.

In conclusion, a therapeutic approach to IVD degeneration involving enhanced tissue repair by exogenous growth factors may be clinically important, but more research is needed to address the efficacy, duration of action, safety, and adverse effects of the growth factors administered in vivo.

\section{Gene therapy}

In gene therapy-based regenerative medicine, messenger RNA can be degraded to decrease the level of expression of relevant genes or exogenous genes can be inserted into cells by means of (non-) viral vectors to increase gene expression [85]. Once the transferred gene is functional, the genetically modified cells can produce the desired product (e.g. a specific growth factor) in a continuous fashion with long-lasting effects [86]. Major barriers to the clinical use of gene therapy, however, include transfection efficiency, the creation of long-term effects, the difficulty of controlling cell proliferation, ectopic transfection, disease transmission, patient-specific dose responses, immune reactions against viral proteins, possible side effects, and ethical issues $[87,88]$. For these reasons, gene therapy has not been used in a clinical setting yet.

\section{Drawbacks of regenerative treatment strategies for IVD degeneration}

Regenerative treatment strategies have some drawbacks. Firstly, early identification of IVD degeneration is essential to prevent the occurrence of IVD disease. Early IVD degeneration can be detected by means of MRI studies, but in 
veterinary practise this diagnostic tool is typically only used when clinical signs are profound. In the case of early IVD degeneration with minor clinical signs, there is the ethical issue of whether the risks of an intradiscal injection are not higher than the benefit that may be expected from the novel regenerative treatment [89]. Secondly, several celland growth factor-based regenerative treatment strategies have been tested in vitro and in vivo in animal models with experimentally induced IVD degeneration. As CD breed dogs have proven a suitable animal model of naturally occurring IVD degeneration $[9,13]$, we advocate using this model to assess the (side) effects of novel regenerative treatments. NP tissue from CD and NCD dogs show differences in gene expression profiles [14] and, therefore, future studies should aim at determining whether CD and NCD dogs also respond differently on IVD regenerative treatments. Thirdly, the performed regenerative IVD studies show halting of degeneration (by increased disc height, proteoglycan or water content, and improved clinical status of patients during follow-up), but it is not known whether the cellbased IVD treatment strategies were actually able to regenerate NP tissue. Therefore, a critical analysis of study results is important, for instance by assessing how close the regenerated IVD is compared with a healthy IVD. Fourthly, the severity of the IVD degeneration possibly influences the therapeutic effect of injected cells and/or growth factors, since degenerated CLCs may have lost their chondrogenic potential and the effect of injected cells and/or growth factors may differ between early and severely degenerated IVDs [90]. These aspects should also be investigated in future studies. Fifthly, all regenerative strategies based on injectable treatments may cause side effects. Cell leakage after intradiscal BMSC injection has been reported to induce osteophyte formation in a rabbit IVD degeneration model [91]. Furthermore, the dose of growth factor to be used needs to be fine-tuned. For example, intradiscal injection of bone morphogenetic protein-2 (BMP-2) induced degenerative changes [92] and weekly intradiscal treatment with growth and differentiation factor-5 (GDF-5) or insulin-like growth factor-1 (IGF-1) resulted in inflammatory reactions in the adjacent vertebrae and connective tissue infiltrates in the NP, causing the IVD to collapse [93]. The latter was also noted in IVDs injected with saline and may be caused by multiple needle insertions [93]. Also, misplacement of recombinant gene therapy products has been associated with lower extremity paralysis after intradural injection, and with paraesthesia, systemic illness, and death after epidural injection $[94,95]$. Furthermore, the sudden acceleration of the cell reproductive cycle by growth factor or gene therapy treatment has been linked with chromosomal translocations or tumorigenesis [32]. Lastly, a meta-analysis demonstrated that treatment of a degenerated IVD with cells and biomaterials showed better results on disc height restoration and MRI T2 signal intensity than treatment with cells or biomaterial alone. However, none of the treatments could fully restore the disc height or achieve the same MRI T2 signal intensity as the healthy disc [96].

\section{Current regenerative treatments in human patients}

Nearly three-quarters of the human population will be affected by low back pain at some stage in their lives [23]. While this condition is multifactorial, IVD degeneration is one of its major causes, involved in at least $40 \%$ of chronic back pain cases [97]. As no effective therapies to retard or reverse disc degeneration have yet been devised, there is huge interest in potential regenerative treatments for human patients. Therefore, over the past few years, several human clinical phase I (safety) and II (efficacy) cell-based trials have been initiated.

In the Euro Disc study, CLCs were obtained from 112 human patients with IVD herniation who underwent discectomy, subsequently culture-expanded and after 12 weeks percutaneously re-injected into the IVD [23]. Interim analysis revealed that human patients receiving autologous CLC transplantation experienced a greater pain reduction after 2 years and had a higher IVD fluid content on MRI than patients who did not undergo CLC transplantation after discectomy [23]. Recently, ten human patients with lumbar IVD disease treated with an intradiscal BMSC injection showed diminished pain and disability and a significantly elevated IVD water content (MRI) at the 1-year follow-up [98]. The same research group is currently performing a clinical study on the treatment of IVD disease with allogeneic BMSCs in twenty-four human patients (http://clinicaltrials.gov/ show/NCT01860417). Furthermore, another phase II clinical trial enrolled 100 human patients with a single painful, degenerated lumbar IVD. Interim analysis of $50 \%$ of the patients after 6 months follow-up indicated a greater reduction in low back pain and an improvement in function in patients receiving $6^{*} 10^{6}$ immunoselected and culture-expanded MSCs compared with control patients. The MRI status of the injected IVD, however, was not affected by the treatment. No cell-related safety issues were encountered in this trial, although the patients receiving $18^{*} 10^{6}$ MSCs showed a higher incidence of adverse effects (http://clinicaltrials.gov/show/NCT01290367).

Lastly, several human growth factor-based phase I/II clinical trials were started to evaluate the safety, tolerability, and preliminary effectiveness of intradiscal delivery of growth and differentiation factor-5 (GDF-5) as compared with placebo (sterile water/vehicle control) in human patients with early lumbar disc degeneration in the United States, Australia, and the Republic of Korea. Clinical and safety outcomes in these trials are the development of adverse events and the neurological status of patients (http://clinicaltrials. gov/show/: NCT00813813, NCT01124006, NCT01158924, and NCT01182337). 
Over the past few years, both human and veterinary medicine have recognized the importance of the 'One Health' concept: bringing together human and animal health for new medical solutions, advantageous for humans as well as animals. Dogs are the only animals that spontaneously develop IVD disease that is diagnosed and treated, both medically and surgically, in the same way as in humans. Our research group has previously shown that the gross pathology, histopathology, GAG content, and MMP-2 activity of human and canine IVDs were similar in all different stages of IVD degeneration [9]. Only some differences between human and canine IVDs were found, such as the absence of growth plates in developing human vertebrae, thicker cartilaginous endplates and more pronounced endplate irregularities in humans with increasing severity of IVD degeneration [9]. Although the canine IVDs were smaller than the human IVDs, the ratio of NP area/IVD area was similar in the two species [9]. These facts indicate that human and canine IVD degeneration is comparable at many different levels and that humans and dogs can benefit from each other by being a suitable model for the other species. Human and canine patients with IVD degeneration can thus be used as a study population to investigate the mechanisms of degeneration and potential regenerative treatments, which is beneficial for both species and suits the 'One Health' concept.

\section{Conclusions}

MSC-based regenerative treatment of the degenerated IVD seems promising. Clinical indications for intradiscal injection of MSCs are (a) treatment of discogenic pain without severe compression and/or neurologic deficits and (b) treatment of the adjacent degenerated discs during decompressive spinal surgery. Percutaneous intradiscal injection is technically feasible in dogs [21-23]. This altogether paves the way for prospective phase I-II clinical trials of minimally invasive cell- or growth factor-based treatment in canine patients with IVD degeneration and disease.

New strategies concentrate on enhancing the regenerative potential of MSCs by growth factors, including those that are specifically secreted by the NCs. Moreover, the conditions under which the regenerative treatment may achieve maximal MSC and resident NP cell performance - even in advanced stages of IVD degeneration - could be improved by creating an optimal biomechanical environment.

\section{Additional file}

Additional file 1: Growth factors tested in vivo in animal models with experimentally induced intervertebral disc (IVD) degeneration.

\section{Abbreviations}

AF: Annulus fibrosus; ASC: Adipose-derived stem cell; BMP-2: Bone morphogenetic protein-2; BMSC: Bone marrow-derived stem cell; CD: Chondrodystrophic; CLC: Chondrocyte-like cell; CTGF: Connective tissue growth factor; DH: Disc height; ECM: Extracellular matrix; EP: End plate; GAG: Glycosaminoglycan; GDF-5: Growth and differentiation factor-5; IGF-1: Isulin-like growth factor-1; IVD: Intervertebral disc; MSC: Mesenchymal stromal (stem) cells; MMP: Matrix metalloproteinase; MRI: Magnetic resonance imaging; NC: Notochordal cell; NCCM: Notochordal cell conditioned medium; NCD: Non-chondrodystrophic; NP: Nucleus pulposus; NPPC: Nucleus pulposus progenitor cell.

\section{Competing interests}

The authors declare that they have no competing interests.

\section{Authors' contributions}

FB mined and analyzed the data, participated in the design of the review, and drafted the manuscript. NW and LP assisted in drafting the manuscript. $\mathrm{Kl}$ participated in the design of the review and helped to draft the manuscript. BM and MT conceived the study, helped to draft the manuscript, and coordinated the process. All authors read and approved the final manuscript.

\section{Acknowledgements}

We are very grateful to Ms. Jane Sykes for language corrections.

\section{Author details}

${ }^{1}$ Department of Clinical Sciences of Companion Animals, Faculty of Veterinary Medicine, Utrecht University, Utrecht, Netherlands. ${ }^{2}$ Department of Biomedical Engineering, Eindhoven University of Technology, Eindhoven, Netherlands. ${ }^{3}$ Department of Orthopaedics, University Medical Center Utrecht, Utrecht, Netherlands.

Received: 6 September 2013 Accepted: 31 December 2013

Published: 4 January 2014

\section{References}

1. Risbud MV, Schaer TP, Shapiro IM: Toward an understanding of the role of notochordal cells in the adult intervertebral disc: from discord to accord. Dev Dyn 2010, 239(8):2141-2148.

2. Bergknut N, Smolders LA, Grinwis GC, Hagman R, Lagerstedt AS, Hazewinkel HA, Tryfonidou MA, Meij BP: Intervertebral disc degeneration in the dog. Part 1: Anatomy and physiology of the intervertebral disc and characteristics of intervertebral disc degeneration. Vet J 2013, 195(3):282-291.

3. Risbud MV, Shapiro IM: Notochordal cells in the adult intervertebral disc: new perspective on an old question. Crit Rev Eukaryot Gene Expr 2011, 21(1):29-41.

4. Hunter CJ, Matyas JR, Duncan NA: Cytomorphology of notochordal and chondrocytic cells from the nucleus pulposus: a species comparison. J Anat 2004, 205(5):357-362.

5. Smolders LA, Bergknut N, Grinwis GC, Hagman R, Lagerstedt AS, Hazewinkel HA, Tryfonidou MA, Meij BP: Intervertebral disc degeneration in the dog. Part 2: Chondrodystrophic and non-chondrodystrophic breeds. Vet J 2013, 195(3):292-299.

6. Bergknut N, Meij BP, Hagman R, de Nies KS, Rutges JP, Smolders LA, Creemers LB, Lagerstedt AS, Hazewinkel HA, Grinwis GC: Intervertebral disc disease in dogs - part 1: a new histological grading scheme for classification of intervertebral disc degeneration in dogs. Vet J 2013 195(2):156-163.

7. Sakai D, Mochida J, Yamamoto Y, Nomura T, Okuma M, Nishimura K, Nakai T, Ando K, Hotta T: Transplantation of mesenchymal stem cells embedded in Atelocollagen gel to the intervertebral disc: a potential therapeutic model for disc degeneration. Biomaterials 2003, 24(20):3531-3541.

8. Hunter CJ, Matyas JR, Duncan NA: The notochordal cell in the nucleus pulposus: a review in the context of tissue engineering. Tissue Eng 2003, 9(4):667-677.

9. Bergknut N, Rutges JP, Kranenburg HJ, Smolders LA, Hagman R, Smidt HJ, Lagerstedt AS, Penning LC, Voorhout G, Hazewinkel HA, Grinwis GC, Creemers LB, Meij BP, Dhert WJ: The dog as an animal model for intervertebral disc degeneration? Spine (Phila Pa 1976) 2012, 37(5):351-358. 
10. Erwin WM, Islam D, Eftekarpour E, Inman RD, Karim MZ, Fehlings MG: Intervertebral disc-derived stem cells: implications for regenerative medicine and neural repair. Spine (Phila Pa 1976) 2013, 38(3):211-216.

11. Meij BP, Bergknut N: Degenerative lumbosacral stenosis in dogs. Vet Clin North Am Small Anim Pract 2010, 40(5):983-1009.

12. Smolders LA, Kingma I, Bergknut N, van der Veen AJ, Dhert WJ, Hazewinkel HA, van Dieen JH, Meij BP: Biomechanical assessment of the effects of decompressive surgery in non-chondrodystrophic and chondrodystrophic canine multisegmented lumbar spines. Eur Spine J 2012 21(9):1692-1699.

13. Sakai D, Nakai T, Mochida J, Alini M, Grad S: Differential phenotype of intervertebral disc cells: microarray and immunohistochemical analysis of canine nucleus pulposus and anulus fibrosus. Spine (Phila Pa 1976) 2009, 34(14):1448-1456.

14. Smolders LA, Meij BP, Onis D, Riemers FM, Bergknut N, Wubbolts R, Grinwis GC, Houweling M, Groot Koerkamp MJ, van Leenen D, Holstege FC, Hazewinkel HA, Creemers LB, Penning LC, Tryfonidou MA: Gene expression profiling of early intervertebral disc degeneration reveals a down-regulation of canonical Wnt signaling and caveolin-1 expression: implications for development of regenerative strategies. Arthritis Res Ther 2013, 15(1):R23.

15. van Dijk BG, Potier E, Ito K: Long-term culture of bovine nucleus pulposus explants in a native environment. Spine J 2013, 13(4):454-463.

16. Urban JP, Maroudas A: Swelling of the intervertebral disc in vitro. Connect Tissue Res 1981, 9(1):1-10

17. van Dijk B, Potier E, Ito K: Culturing bovine nucleus pulposus explants by balancing medium osmolarity. Tissue Eng Part C Methods 2011, 17(11):1089-1096

18. Gantenbein B, Grunhagen T, Lee CR, van Donkelaar CC, Alini M, Ito K: An in vitro organ culturing system for intervertebral disc explants with vertebral endplates: a feasibility study with ovine caudal discs. Spine (Phila Pa 1976) 2006, 31(23):2665-2673.

19. Illien-Junger S, Gantenbein-Ritter B, Grad S, Lezuo P, Ferguson SJ, Alini M, Ito $K$ : The combined effects of limited nutrition and high-frequency loading on intervertebral discs with endplates. Spine (Phila Pa 1976) 2010, 35(19):1744-1752.

20. Alini M, Eisenstein SM, Ito K, Little C, Kettler AA, Masuda K, Melrose J, Ralphs J, Stokes I, Wilke HJ: Are animal models useful for studying human disc disorders/degeneration? Eur Spine J 2008, 17(1):2-19.

21. Ganey T, Libera J, Moos V, Alasevic O, Fritsch KG, Meisel HJ, Hutton WC: Disc chondrocyte transplantation in a canine model: a treatment for degenerated or damaged intervertebral disc. Spine (Phila Pa 1976) 2003, 28(23):2609-2620

22. Meisel HJ, Siodla V, Ganey T, Minkus Y, Hutton WC, Alasevic OJ: Clinical experience in cell-based therapeutics: disc chondrocyte transplantation A treatment for degenerated or damaged intervertebral disc. Biomol Eng 2007, 24(1):5-21

23. Hohaus C, Ganey TM, Minkus Y, Meisel HJ: Cell transplantation in lumbar spine disc degeneration disease. Eur Spine J 2008, 17(4):492-503.

24. Hiyama A, Mochida J, Iwashina T, Omi H, Watanabe T, Serigano K, Tamura F, Sakai D: Transplantation of mesenchymal stem cells in a canine disc degeneration model. J Orthop Res 2008, 26(5):589-600.

25. Ganey T, Hutton WC, Moseley T, Hedrick M, Meisel HJ: Intervertebral disc repair using adipose tissue-derived stem and regenerative cells: experiments in a canine model. Spine (Phila Pa 1976) 2009, 34(21):2297-2304

26. Serigano K, Sakai D, Hiyama A, Tamura F, Tanaka M, Mochida J: Effect of cell number on mesenchymal stem cell transplantation in a canine disc degeneration model. J Orthop Res 2010, 28(10):1267-1275.

27. Henriksson HB, Brisby $H$ : Development and regeneration potential of the mammalian intervertebral disc. Cells Tissues Organs 2013, 197(1):1-13.

28. Nomura T, Mochida J, Okuma M, Nishimura K, Sakabe K: Nucleus pulposus allograft retards intervertebral disc degeneration. Clin Orthop Relat Res 2001, 389:94-101.

29. Nishimura K, Mochida J: Percutaneous reinsertion of the nucleus pulposus. An experimental study. Spine (Phila Pa 1976) 1998, 23(14):1531-1538.

30. Yang F, Leung W, Luk KD, Chan D, Cheung KM: Mesenchymal stem cells arrest intervertebral disc degeneration through chondrocytic differentiation and stimulation of endogenous cells. Mol Ther 2009, 17(11):1959-1966.

31. Takada T, Nishida K, Doita M, Kurosaka M: Fas ligand exists on intervertebral disc cells: a potential molecular mechanism for immune privilege of the disc. Spine (Phila Pa 1976) 2002, 27(14):1526-1530.
32. Watanabe T, Sakai D, Yamamoto $Y$, I washina T, Serigano K, Tamura F, Mochida $\mathrm{J}$ : Human nucleus pulposus cells significantly enhanced biological properties in a coculture system with direct cell-to-cell contact with autologous mesenchymal stem cells. J Orthop Res 2010, 28(5):623-630.

33. Okuma M, Mochida J, Nishimura K, Sakabe K, Seiki K: Reinsertion of stimulated nucleus pulposus cells retards intervertebral disc degeneration: an in vitro and in vivo experimental study. J Orthop Res 2000, 18(6):988-997.

34. Yamamoto Y, Mochida J, Sakai D, Nakai T, Nishimura K, Kawada H, Hotta T: Upregulation of the viability of nucleus pulposus cells by bone marrowderived stromal cells: significance of direct cell-to-cell contact in coculture system. Spine (Phila Pa 1976) 2004, 29(14):1508-1514

35. Gaetani P, Torre ML, Klinger M, Faustini M, Crovato F, Bucco M, Marazzi M, Chlapanidas T, Levi D, Tancioni F, Vigo D, Rodriguez y Baena R: Adiposederived stem cell therapy for intervertebral disc regeneration: an in vitro reconstructed tissue in alginate capsules. Tissue Eng Part A 2008, 14(8):1415-1423.

36. Lu ZF, Zandieh Doulabi B, Wuisman PI, Bank RA, Helder MN: Differentiation of adipose stem cells by nucleus pulposus cells: configuration effect. Biochem Biophys Res Commun 2007, 359(4):991-996.

37. Mochida J: New strategies for disc repair: novel preclinical trials. $J$ Orthop Sci 2005, 10(1):112-118

38. Svanvik T, Henriksson HB, Karlsson C, Hagman M, Lindahl A, Brisby H: Human disk cells from degenerated disks and mesenchymal stem cells in co-culture result in increased matrix production. Cells Tissues Organs 2010, 191(1):2-11.

39. Yang SH, Wu CC, Shih TT, Sun YH, Lin FH: In vitro study on interaction between human nucleus pulposus cells and mesenchymal stem cells through paracrine stimulation. Spine (Phila Pa 1976) 2008, 33(18):1951-1957.

40. Acharya C, Adesida A, Zajac P, Mumme M, Riesle J, Martin I, Barbero A: Enhanced chondrocyte proliferation and mesenchymal stromal cells chondrogenesis in coculture pellets mediate improved cartilage formation. J Cell Physiol 2012, 227(1):88-97.

41. McCann MR, Bacher CA, Seguin CA: Exploiting notochord cells for stem cell-based regeneration of the intervertebral disc. J Cell Commun Signal 2011, 5(1):39-43.

42. Chen S, Emery SE, Pei M: Coculture of synovium-derived stem cells and nucleus pulposus cells in serum-free defined medium with supplementation of transforming growth factor-beta1: a potential application of tissue-specific stem cells in disc regeneration. Spine (Phila Pa 1976) 2009, 34(12):1272-1280.

43. Bartholomew A, Sturgeon C, Siatskas M, Ferrer K, Mclntosh K, Patil S, Hardy W, Devine S, Ucker D, Deans R, Moseley A, Hoffman R: Mesenchymal stem cells suppress lymphocyte proliferation in vitro and prolong skin graft survival in vivo. Exp Hematol 2002, 30(1):42-48.

44. Meirelles Lda S, Fontes AM, Covas DT, Caplan Al: Mechanisms involved in the therapeutic properties of mesenchymal stem cells. Cytokine Growth Factor Rev 2009, 20(5-6):419-427.

45. Tse WT, Pendleton JD, Beyer WM, Egalka MC, Guinan EC: Suppression of allogeneic T-cell proliferation by human marrow stromal cells: implications in transplantation. Transplantation 2003, 75(3):389-397.

46. Strassburg S, Hodson NW, Hill PI, Richardson SM, Hoyland JA: Bi-directiona exchange of membrane components occurs during co-culture of mesenchymal stem cells and nucleus pulposus cells. PLoS One 2012, 7(3):e33739.

47. Crevensten G, Walsh AJ, Ananthakrishnan D, Page P, Wahba GM, Lotz JC, Berven S: Intervertebral disc cell therapy for regeneration: mesenchymal stem cell implantation in rat intervertebral discs. Ann Biomed Eng 2004, 32(3):430-434

48. Sakai D, Mochida J, Iwashina T, Hiyama A, Omi H, Imai M, Nakai T, Ando K, Hotta T: Regenerative effects of transplanting mesenchymal stem cells embedded in atelocollagen to the degenerated intervertebral disc. Biomaterials 2006, 27(3):335-345.

49. Zhang YG, Guo X, Xu P, Kang LL, Li J: Bone mesenchymal stem cells transplanted into rabbit intervertebral discs can increase proteoglycans. Clin Orthop Relat Res 2005, 430:219-226.

50. Sakai D, Mochida J, Iwashina T, Watanabe T, Nakai T, Ando K, Hotta T: Differentiation of mesenchymal stem cells transplanted to a rabbit degenerative disc model: potential and limitations for stem cell therapy in disc regeneration. Spine (Phila Pa 1976) 2005, 30(21):2379-2387.

51. Chun HJ, Kim YS, Kim BK, Kim EH, Kim JH, Do BR, Hwang SJ, Hwang JY, Lee YK: Transplantation of human adipose-derived stem cells in a rabbit 
model of traumatic degeneration of lumbar discs. World Neurosurg 2012, 78(3-4):364-371.

52. Jin ES, Min J, Jeon SR, Choi KH, Jeong JH: Analysis of molecular expression in adipose tissue-derived mesenchymal stem cells : prospects for use in the treatment of intervertebral disc degeneration. J Korean Neurosurg Soc 2013, 53(4):207-212.

53. Steck E, Bertram H, Abel R, Chen B, Winter A, Richter W: Induction of intervertebral disc-like cells from adult mesenchymal stem cells. Stem Cells 2005, 23(3):403-411.

54. Bertolo A, Mehr M, Aebli N, Baur M, Ferguson SJ, Stoyanov JV: Influence of different commercial scaffolds on the in vitro differentiation of human mesenchymal stem cells to nucleus pulposus-like cells. Eur Spine J 2012, 21:826-838.

55. Richardson SM, Hughes N, Hunt JA, Freemont AJ, Hoyland JA: Human mesenchymal stem cell differentiation to NP-like cells in chitosanglycerophosphate hydrogels. Biomaterials 2008, 29(1):85-93.

56. Sakai D, Nakamura Y, Nakai T, Mishima T, Kato S, Grad S, Alini M, Risbud MV, Chan D, Cheah KS, Yamamura K, Masuda K, Okano H, Ando K, Mochida J: Exhaustion of nucleus pulposus progenitor cells with ageing and degeneration of the intervertebral disc. Nat Commun 2012, 3:1264.

57. Huang S, Leung VY, Long D, Chan D, Lu WW, Cheung KM, Zhou G: Coupling of small leucine-rich proteoglycans to hypoxic survival of a progenitor cell-like subpopulation in Rhesus Macaque intervertebral disc. Biomaterials 2013, 34(28):6548-6558.

58. Kim JH, Deasy BM, Seo HY, Studer RK, Vo NV, Georgescu HI, Sowa GA, Kang JD: Differentiation of intervertebral notochordal cells through live automated cell imaging system in vitro. Spine (Phila Pa 1976) 2009, 34(23):2486-2493.

59. Korecki CL, Taboas JM, Tuan RS, latridis JC: Notochordal cell conditioned medium stimulates mesenchymal stem cell differentiation toward a young nucleus pulposus phenotype. Stem Cell Res Ther 2010, 1(2):18.

60. Purmessur D, Schek RM, Abbott RD, Ballif BA, Godburn KE, latridis JC: Notochordal conditioned media from tissue increases proteoglycan accumulation and promotes a healthy nucleus pulposus phenotype in human mesenchymal stem cells. Arthritis Res Ther 2011, 13(3):R81.

61. Abbott RD, Purmessur D, Monsey RD, latridis JC: Regenerative potential of TGFbeta3 + Dex and notochordal cell conditioned media on degenerated human intervertebral disc cells. J Orthop Res 2012, 30(3):482-488.

62. Aguiar DJ, Johnson SL, Oegema TR: Notochordal cells interact with nucleus pulposus cells: regulation of proteoglycan synthesis. Exp Cell Res 1999, 246(1):129-137.

63. Erwin WM, Inman RD: Notochord cells regulate intervertebral disc chondrocyte proteoglycan production and cell proliferation. Spine (Phila Pa 1976) 2006, 31(10):1094-1099.

64. Allon AA, Butcher K, Schneider RA, Lotz JC: Structured coculture of mesenchymal stem cells and disc cells enhances differentiation and proliferation. Cells Tissues Organs 2012, 196(2):99-106.

65. Xie LW, Fang H, Chen AM, Li F: Differentiation of rat adipose tissuederived mesenchymal stem cells towards a nucleus pulposus-like phenotype in vitro. Chin J Traumatol 2009, 12(2):98-103.

66. Erwin WM, Islam D, Inman RD, Fehlings MG, Tsui FW: Notochordal cells protect nucleus pulposus cells from degradation and apoptosis: implications for the mechanisms of intervertebral disc degeneration. Arthritis Res Ther 2011, 13(6):R215.

67. Erwin WM, Ashman K, O'Donnel P, Inman RD: Nucleus pulposus notochord cells secrete connective tissue growth factor and up-regulate proteoglycan expression by intervertebral disc chondrocytes. Arthritis Rheum 2006, 54 (12):3859-3867.

68. Erwin WM: The Notochord, Notochordal cell and CTGF/CCN-2: ongoing activity from development through maturation. I Cell Commun Signal 2008, 2(3-4):59-65.

69. Erwin WM, Las Heras F, Islam D, Fehlings MG, Inman RD: The regenerative capacity of the notochordal cell: tissue constructs generated in vitro under hypoxic conditions. J Neurosurg Spine 2009, 10(6):513-521.

70. Kim KW, Ha KY, Lee JS, Nam SW, Woo YK, Lim TH, An HS: Notochordal cells stimulate migration of cartilage end plate chondrocytes of the intervertebral disc in in vitro cell migration assays. Spine J 2009, 9(4):323-329.

71. Zavala G, Vazquez-Nin GH: Analysis of nuclear ribonucleoproteic structures during notochordal cell differentiation and maturation in chick embryos. Anat Rec 2000, 259(2):113-123.
72. Chen J, Yan W, Setton LA: Molecular phenotypes of notochordal cells purified from immature nucleus pulposus. Eur Spine J 2006, 15:303-311.

73. Vujovic S, Henderson S, Presneau N, Odell E, Jacques TS, Tirabosco R, Boshoff C, Flanagan AM: Brachyury, a crucial regulator of notochordal development, is a novel biomarker for chordomas. J Pathol 2006, 209(2):157-165.

74. Yang F, Leung VY, Luk KD, Chan D, Cheung KM: Injury-induced sequential transformation of notochordal nucleus pulposus to chondrogenic and fibrocartilaginous phenotype in the mouse. J Pathol 2009, 218(1):113-121.

75. Guehring T, Urban JP, Cui Z, Tirlapur UK: Noninvasive 3D vital imaging and characterization of notochordal cells of the intervertebral disc by femtosecond near-infrared two-photon laser scanning microscopy and spatial-volume rendering. Microsc Res Tech 2008, 71(4):298-304.

76. Minogue BM, Richardson SM, Zeef LA, Freemont AJ, Hoyland JA: Transcriptional profiling of bovine intervertebral disc cells: implications for identification of normal and degenerate human intervertebral disc cell phenotypes. Arthritis Res Ther 2010, 12(1):R22.

77. Cappello R, Bird JL, Pfeiffer D, Bayliss MT, Dudhia J: Notochordal cell produce and assemble extracellular matrix in a distinct manner, which may be responsible for the maintenance of healthy nucleus pulposus. Spine (Phila Pa 1976) 2006, 31(8):873-882.

78. Choi KS, Cohn MJ, Harfe BD: Identification of nucleus pulposus precursor cells and notochordal remnants in the mouse: implications for disk degeneration and chordoma formation. Dev Dyn 2008, 237(12):3953-3958.

79. McCann MR, Tamplin OJ, Rossant J, Seguin CA: Tracing notochord-derived cells using a Noto-cre mouse: implications for intervertebral disc development. Dis Model Mech 2012, 5(1):73-82.

80. Hoogendoorn R: Notochordal cells in mature caprine intervertebral discs. Eur Cells and Materials 2005, 10(3):59.

81. Gilson A, Dreger M, Urban JP: Differential expression level of cytokeratin 8 in cells of the bovine nucleus pulposus complicates the search for specific intervertebral disc cell markers. Arthritis Res Ther 2010, 12(1):R24.

82. Rutges J, Creemers LB, Dhert W, Milz S, Sakai D, Mochida J, Alini M, Grad S: Variations in gene and protein expression in human nucleus pulposus in comparison with annulus fibrosus and cartilage cells: potential associations with aging and degeneration. Osteoarthritis Cartilage 2010, 18(3):416-423.

83. Rastogi A, Thakore P, Leung A, Benavides M, Machado M, Morschauser MA, Hsieh AH: Environmental regulation of notochordal gene expression in nucleus pulposus cells. J Cell Physiol 2009, 220(3):698-705.

84. Masuda K: Biological repair of the degenerated intervertebral disc by the injection of growth factors. Eur Spine J 2008, 17:441-451.

85. Nishida K, Doita M, Takada T, Kakutani K, Miyamoto H, Shimomura T, Maeno K, Kurosaka M: Sustained transgene expression in intervertebral disc cells in vivo mediated by microbubble-enhanced ultrasound gene therapy. Spine (Phila Pa 1976) 2006, 31(13):1415-1419.

86. Nishida K, Kang JD, Gilbertson LG, Moon SH, Suh JK, Vogt MT, Robbins PD, Evans $\mathrm{CH}$ : Modulation of the biologic activity of the rabbit intervertebral disc by gene therapy: an in vivo study of adenovirus-mediated transfer of the human transforming growth factor beta 1 encoding gene. Spine (Phila Pa 1976) 1999, 24(23):2419-2425.

87. Maerz T, Herkowitz H, Baker K: Molecular and genetic advances in the regeneration of the intervertebral disc. Surg Neurol Int 2013, 4:94-S105.

88. Fassett DR, Kurd MF, Vaccaro AR: Biologic solutions for degenerative disk disease. J Spinal Disord Tech 2009, 22(4):297-308.

89. Niemansburg SL, van Delden JJ, Dhert WJ, Bredenoord AL: Regenerative medicine interventions for orthopedic disorders: ethical issues in the translation into patients. Regen Med 2013, 8(1):65-73.

90. Ho G, Leung VY, Cheung KM, Chan D: Effect of severity of intervertebral disc injury on mesenchymal stem cell-based regeneration. Connect Tissue Res 2008, 49(1):15-21.

91. Vadala G, Sowa G, Hubert M, Gilbertson LG, Denaro V, Kang JD: Mesenchymal stem cells injection in degenerated intervertebral disc: cell leakage may induce osteophyte formation. J Tissue Eng Regen Med 2012, 6(5):348-355.

92. Huang KY, Yan JJ, Hsieh CC, Chang MS, Lin RM: The in vivo biological effects of intradiscal recombinant human bone morphogenetic protein- 2 on the injured intervertebral disc: an animal experiment. Spine (Phila Pa 1976) 2007, 32(11):1174-1180.

93. Walsh AJ, Bradford DS, Lotz JC: In vivo growth factor treatment of degenerated intervertebral discs. Spine (Phila Pa 1976) 2004, 29(2):156-163. 
94. Wallach CJ, Kim JS, Sobajima S, Lattermann C, Oxner WM, McFadden K, Robbins PD, Gilbertson LG, Kang JD: Safety assessment of intradiscal gene transfer: a pilot study. Spine J 2006, 6(2):107-112.

95. Vadala G, Sowa GA, Kang JD: Gene therapy for disc degeneration. Expert Opin Biol Ther 2007, 7(2):185-196.

96. Mehrkens A, Muller AM, Valderrabano V, Scharen S, Vavken P: Tissue engineering approaches to degenerative disc disease-a meta-analysis of controlled animal trials. Osteoarthritis Cartilage 2012, 20(11):1316-1325.

97. Freemont AJ: The cellular pathobiology of the degenerate intervertebral disc and discogenic back pain. Rheumatology (Oxford) 2009, 48(1):5-10.

98. Orozco L, Soler R, Morera C, Alberca M, Sanchez A, Garcia-Sancho J: Intervertebral disc repair by autologous mesenchymal bone marrow cells: a pilot study. Transplantation 2011, 92(7):822-828.

doi:10.1186/1746-6148-10-3

Cite this article as: Bach et al:: Potential regenerative treatment strategies for intervertebral disc degeneration in dogs. BMC Veterinary Research 2014 10:3.

\section{Submit your next manuscript to BioMed Central and take full advantage of:}

- Convenient online submission

- Thorough peer review

- No space constraints or color figure charges

- Immediate publication on acceptance

- Inclusion in PubMed, CAS, Scopus and Google Scholar

- Research which is freely available for redistribution 